\title{
Hybrid Two-stroke Motor Drive
}

\author{
Z. Bureš* \\ Department of Communication and Information Systems, University of Defence, Brno, Czech Republic \\ *Corresponding author: zbynek.bures@unob.cz \\ M. Šula \\ MSR Engines Ltd., Brno, Czech Republic \\ V. Př̀nosil \\ Department of Informatics Technology, Faculty of Informatics, Masaryk University, Brno, Czech Republic
}

DOI: $10.2478 / \mathrm{v} 10158-012-0005-4$

\begin{abstract}
The article describes the implemented and tested K.E.R.S. (Kinetic Energy Recuperation System) system. The system uses braking energy to charge the operative source of energy. The captured energy is used to enhance energy for the subsequent acceleration of the combustion engine.
\end{abstract}

KEY WORDS: KERS system, supercapacitor, additional torque.

\section{INTRODUCTION - TECHNOLOGY, PRODUCT OR SERVICE DESCRIPTION}

The project aims to develop a braking energy recuperation system. It is possible to use this system with single-track vehicles (especially scooters, race bikes) and small two-track vehicles with a combustion engine of up to $50 \mathrm{~kW}$ of power or greater with necessary modifications.

Our goal is to develop a driving unit consisting of a conventional combustion engine and a braking energy recuperation system. This will allow lower levels of both emissions and combustion engine fuel consumption in the acceleration phase or outside the optimal engine working band, and also better engine efficiency dynamics.

The technical side of the solution focuses on improving the combustion engine acceleration which is provided by an additional synchronous electromotor with electronic commutation, alternator, and controlled supercapacitors with charging and discharging based on the requirements of the operator or system itself.

The combustion engine is connected to a synchronous electromotor and a generator. The three-stage generator feeds its output into the three phase synchronous rectifier. The rectified voltage from the rectifier is sent through a controlled disconnector into the supercapacitors. The generated voltage can also be used for supplying the electronic 
equipment of the vehicle with power and for recharging the battery instead of the alternator used in existing models.

The supercapacitors' energy is brought to a controlled regulator of the three-stage engine. The regulator sends its output into a three-stage driving synchronous electromotor with electronic commutation. The disconnector and regulator are controlled electronically.

After switching on the supercapacitors are flat. After starting the combustion engine the generator connects and the supercapacitors are charged. The regulator then initializes and the generator is disconnected. While the vehicle decelerates, electric power recharging the supercapacitors is being generated. The controlled disconnector is in the "connected" mode. After having charged the supercapacitors the controlled disconnector enters the "disconnected" mode and the generator provides only the power required by the electric circuits of the vehicle. While accelerating, the synchronous electromotor is being spun via the regulator, helping with the acceleration. After having used all the supercapacitors' energy, the electromotor turns off. Charging of the supercapacitors can also be forced by the operator, regardless of the deceleration.

The additional power supplied by the electric driving unit can amount to $15 \mathrm{~kW}$ (this being $30 \%$ of the power of the considered combustion engine). This power is limited due to our laboratory equipment and the limited financial resources we have invested in the project. We have a working prototype offering $4 \mathrm{~kW}$ of power.

For this reason we focus on small combustion engines with power up to $50 \mathrm{~kW}$. With the power of the electromotor up to $15 \mathrm{~kW}$ this system allows the running of the combustion engine within the range of the best power/weight/consumption/emissions ratio. This also goes for modes in which conventional engines are the worst - i.e., acceleration. We saw a significant drop in fuel consumption in acceleration modes while making use of the kinetic energy of the vehicle, which is normally wasted during braking.

\section{WORKING PROTOTYPE DESCRIPTION}

We test the device on a city scooter with an engine capacity of $125 \mathrm{ccm}$ (further on referred to as the 'motorcycle' and motoGP $125 \mathrm{ccm}$ from a KTM). The combustion engine is directly connected to a generator and to a synchronous motor through a toothed belt. The motorcycle also features supercapacitors and an electronic controlling system.

While braking the generator connects to the supercapacitors and recharges them. While accelerating the electromotor connects to the combustion engine and adds its power to it. The amount of the additional power depends on the type of electromotor, regulator, and super-capacitors, and the current needs.

While driving, the following signals are fed into the controlling unit:

- braking system pressure,

- throttle valve position,

- current gear,

- revolutions of the combustion engine,

- supercapacitors' voltage,

- recharging current flowing from the generator to the supercapacitors, 
- discharging current flowing from the supercapacitors to the electromotor,

- switch of the forced recharging of the supercapacitors,

- required power mode.

The electronics of the controlling system offers:

- recording for all the parameters in the internal memory for later post-processing,

- information of the recharged level of the supercapacitors,

- predicted time of acceleration,

- predicted time of recharging of the supercapacitors to a specified level in $\%$.

The amount of energy passed from the supercapacitors to the electromotor depends on the throttle valve position, increase of the combustion engine revolutions, the current gear and the supercapacitors' voltage.

The amount of energy passed from the generator to the supercapacitors depends on the braking system pressure, throttle valve position, combustion engine revolutions, the super-capacitors' voltage and the supercapacitors' maximum recharging current and actual track condition.

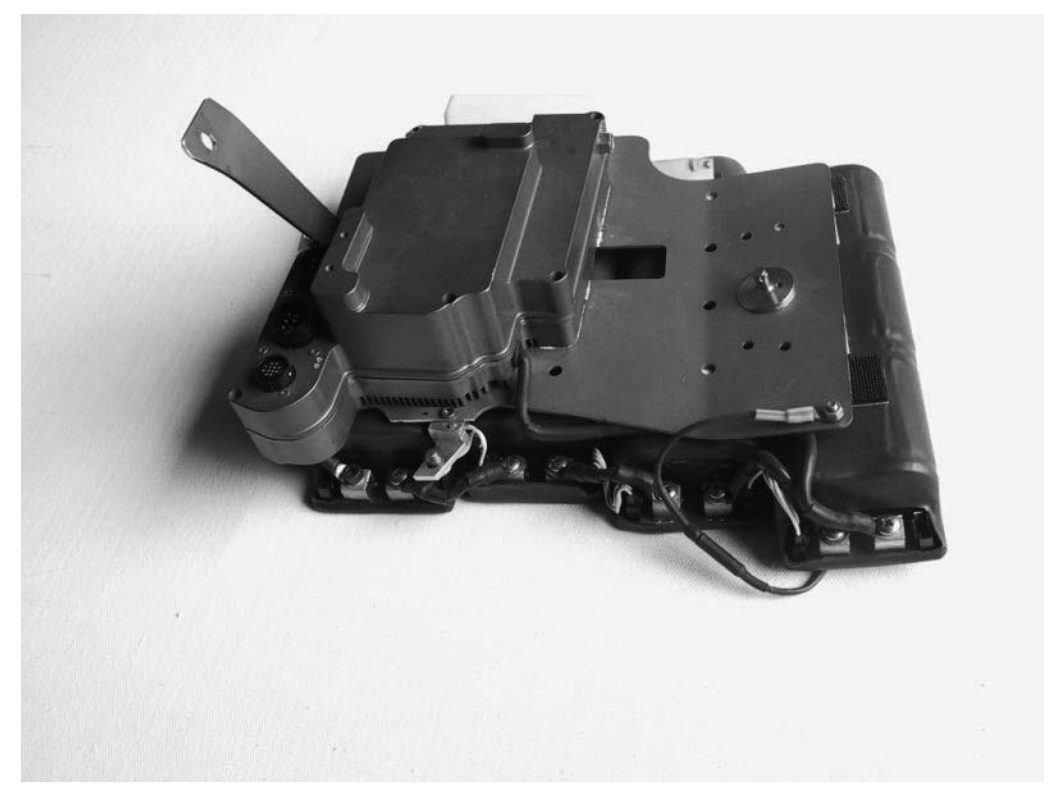

Figure 1: Mechanical realization of the power unit with supercapacitors. 


\section{PRODUCT DEVELOPMENT PLAN, INCLUDING RISK ANALYSIS}

After completing the product the aim is its mass production. Our goal is not to produce it on our own - we want to license the product to producers of small-capacity vehicles and motorcycles. At the moment, we must do the following:

- to finish the product line of $5-15 \mathrm{~kW}$ of power (there is a working prototype of $4 \mathrm{~kW}$ of power). $15 \mathrm{~kW}$ is the technological upper limit that we want to test this being due to financial and technical reasons,

- to test it in real life (install it in existing vehicles, motorcycles, and scooters) and to test the lifespan (various wind conditions, various modes of operation, etc.),

- to finish the intellectual property protection by patent protection and a utility model,

- to establish partnerships and to commercialise the product,

- thanks to its small size, low weight, and compact design, we also consider direct selling of the product to those interested in adding the recuperation feature to their existing vehicles.

\section{PARTNERSHIPS VITAL TO THE SUCCESS OF THE PROJECT}

The product is very interesting for producers of small-capacity vehicles and motorcycles. In order to get to know the market and the technological possibilities of potential producers better, we contacted a well-established European motorcycle producer (we don't disclose the name, this cooperation being confidential at this point) with whom we have cooperated on previous development projects. Additionally, we talked to the representatives of the formula 1 HONDA RACING, Williams, and BMW team who showed a serious interest in our knowledge in this field (before it back out from F1) for new Formula BMW. The main reason for this being that the FEDERATION INTERNATIONALE DE L'AUTOMOBILE (FIA) requires all formula 1 cars to have an energy recuperation system. They confirmed the development direction suggested by us as correct and the only way to get a lightweight and efficient device is through our design. For this reason we added the goal of higher engine-power limits to our originally environmentally friendly concept. This should improve the dynamic features of sport motorcycles and vehicles.

Due to the ongoing patent proceedings concerning the main idea, the negotiations with potential partners is at very early stages. We need to finish the patent protection worldwide, finish another type of working prototype, and prove the efficiency of our solution to the potential partners through gauging and testing. Unfortunately, that is where we are running low on resources at the moment. 


\section{TARGET MARKET DESCRIPTION, INCLUDING SIMPLE FINANCIAL ESTIMATIONS}

Mass production is critical - the current prototype price being $€ 3000$ (over USD 4000). Mass production will make lowering the price to about $€ 300-400$ (USD 400-550) possible. For a price of about $€ 600$ (over USD 800) the capital returns after about $50,000 \mathrm{~km}$ (only from fuel savings calculations based on the European prices of fuel); additionally it is possible to use engines with a smaller capacity and the same dynamics, saving more with newer vehicles (thus motivating buyers to purchase our product). We assessed the market using data for EU markets (specifically the ACEA (European Automobile Manufacturers Association - www.acea.be), statistical data, and the Eurostat statistical office (www.europa.eu/eurostat) ${ }^{*}$.

In the year 2006 there were 15,819,022 personal vehicles ${ }^{\dagger}$ registered in EU 25. Due to its power, our product is only suitable for small vehicles, which are typically used in the city. Nevertheless, this segment is rather strong - it comprises of up to about one third of the total number of cars, and is getting stronger and stronger ${ }^{*}$.

Even when a very low estimate of sales of 100,000 units $^{\S}$ at $€ 500$ with a profit margin of $€ 200$ the gross income is $€ 20$ million (about USD 28 million). Based on our calculations, this gross income is sufficient to cover our development and commercialization costs.

Greater selling opportunities (but with smaller profit margin) can also be expected due to the pressure of the European Commission on lowering the $\mathrm{CO}_{2}$ emissions to the level of $130 \mathrm{~g}$ of $\mathrm{CO}_{2} / \mathrm{km}$ by 2012. ACEA claims the price per car will increase by up to $€ 2500$ on average, we offer a much cheaper solution, at least for small-capacity vehicles.

There is also a demand in the USA and other countries where car transportation is highly concentrated and puts pressure on the environment. The segment of small-capacity vehicles, suitable for fitting our product to, is not so strong outside the EU.*

Another target market is the market of motorcycles - here we also base our calculations on EU 25 data (and here the sales potential is also worldwide; we base our calculation in the EU region only due to data availability). There are more than 1,200,000 motorcycles registered in EU 25 (the total number in use in the EU is over 16,000,000) - and since we are able to produce a recuperation unit of various sizes and power, we can also saturate this market. The pressure of meeting strict emission limits is similar to that in the car industry. The planned production of 100,000 units is a sales estimate on the low side.

The theoretical potential of sales and estimates of financial indicators are very rough with regard to the contemporary situation of the development, but, even so, the potential of our product is very interesting.

\footnotetext{
${ }^{*}$ Relevant statistics available at:

http://epp.eurostat.ec.europa.eu/portal/page? pageid $=0,1136228,045572945 \&$ dad=portal\&_schema=PORTAL

${ }^{\dagger}$ The number of registrations in 1996-2007 is increasing, in 2003 it reached a total of $15,000,000$

* Data for 2003 available only for 9 EU countries (Estonia, Greece, France, Hungary, Lithuania, Austria, Poland, Finland, United Kingdom) mention 1,936,920 vehicles within $1400 \mathrm{~cm} 3$ out of total 6,048,584 newly registered. About one third of newly registered vehicles can use our product directly in contemporary power range (within $15 \mathrm{~kW}$ of electromotor power).

$\S$ The yearly production only of TCPA in CR, producing small vehicles suitable for using our product, amounts to more than 300,000 units.

${ }^{* *}$ With increasing pressure on lowering the greenhouse gas emissions, this segment will probably grow as well - such tendencies to lower the impact of vehicle use on the environment can be seen in California, New York City, and other American centers.
} 


\section{NECESSARY RESOURCES BOTH IN THE SHORT- AND LONG TERM}

Estimated resources (Low mean estimate):

- Finishing - USD 250,000 (wages, technology, material).

- $\quad$ Testing - USD 280,000 (testing vehicles, installation - work + material, testing).

- $\quad$ Patent protection - 10,000 USD (worldwide).

- Commercialisation - at least USD 20-50,000, considering only legal and consultation advice, the commercialisation itself would be financially aided by our partners. No direct commercialization costs are included (start of production 200,000-500,000 USD).

\section{ESTIMATED REDUCTION OF GREENHOUSE GASES AND ITS IMPACT ON SUSTAINABLE DEVELOPMENT}

Up to 20-25 per cent lower fuel consumption, together with reducing the transitional modes of combustion engines, will lead to a significant reduction in emissions. The reduction is most significant while driving in the city (gas-brake driving style), where our product can provide acceleration for up to about $20 \mathrm{sec}^{*}$. Based on our gauging, this is sufficient capacity for reallife driving.

In comparison with existing hybrid products, our solution is much more environmentallyfriendly, due to the components used - it does not contain batteries and other components that are difficult to recycle. The savings are based on making use of braking energy, which is otherwise wasted in the form of heat energy. The product itself is very small and compact (the weight is approx. $6 \mathrm{~kg}$ with $4 \mathrm{~kW}$ of power), which also reduces the energy necessary for the production, making the energy requirements, with regards to the lifespan of the product, rather low. It can replace the currently used alternator and reduce the weight and complexity of the vehicle.

It also allows the use of smaller-capacity engines (less than 1 liter), while keeping the dynamics of a small urban vehicle.

The compact design also allows for fitting the product into existing vehicles, and for increasing the possibilities of hybrid drive use and lowering greenhouse gas emissions. $^{\dagger}$

\footnotetext{
* The amount of decrease in emissions can be estimated based on the fuel consumption savings - but, as mentioned above, this depends on the style of driving.

${ }^{\dagger}$ Based on current fuel prices, this solution is reasonable for modified vehicles for driving more than $30-60,000 \mathrm{~km}$.
} 


\section{TECHNOLOGY, PRODUCT OR SERVICE DESCRIPTION KTM - KERS}

Our goal is to develop a driving unit consisting of a conventional combustion engine and a braking energy recuperation system. This will allow lower levels of both emissions and combustion engine fuel consumption in the acceleration phase, and also better engine efficiency dynamics.

The technical side of the solution focuses on improving the combustion engine acceleration, which is provided by an additional synchronous electromotor with electronic commutation, alternator and controlled supercapacitor with charging and discharging based on the requirements of the operator.

The combustion engine is connected to a synchronous electromotor and a generator. The three-stage generator feeds its output into the rectifier. The rectified voltage from the rectifier is sent through a controlled disconnector into the supercapacitors. The generated voltage can also be used for supplying the electronic equipment of the vehicle with power and for recharging the battery instead of the alternator used in existing models.

The super-capacitors' energy is brought to a controlled regulator of the three-stage engine. The regulator sends its output into a three-stage driving synchronous electromotor with electronic commutation. The disconnector and regulator are controlled electronically.

After switching on the super-capacitors are flat. After starting of the combustion engine the generator connects and the super-capacitors are being charged. Then the regulator initializes and the generator is disconnected. While the vehicle decelerates, electric power recharging the super-capacitors is being generated. The controlled disconnector is in the "connected" mode. After having charged the super-capacitors the controlled disconnector enters the "disconnected" mode and the generator provides only the power required by the electric circuits of the vehicle. While accelerating, the synchronous electromotor is being spun via the regulator, helping with the acceleration. After having used all the super-capacitors' energy the electromotor turns off. Charging of the super-capacitors can be forced also by the operator regardless of the deceleration.

\section{OUR ACQUIRED EXPERIENCES AND PROBLEMS SOLVED DURING THE PROJECT KERS- MOTO GP 125CCM KTM}

During our development we worked step by step on each part. These parts are summarized on the next table.

The results are as follows:

- We made a calculation of all available accumulative sources of the energy (Li-On, Li-Pol, Li-FePo, super-capacitors, flywheel), their advantages and disadvantages. We had to solve the cooling system for the motor and generator.

- Our system is fully autonomous with ABS, AHS, kerbs protection).

- The whole system was tested for two years with approximately $12.000 \mathrm{~km}$. 
- Low budget (paid from private money).

\begin{tabular}{|l|l|}
\hline Component name & $\begin{array}{c}\text { No. } \\
\text { of modification }\end{array}$ \\
\hline Propulsive motor & 8 types \\
\hline Generator & 10 types \\
\hline Converter & 4 types \\
\hline Regulator & 3 types \\
\hline ECU & 3 types \\
\hline SW & 6 versions \\
\hline Implementation (build-up area) & 3 types \\
\hline Component name & $\begin{array}{c}\text { No. } \\
\text { of modification }\end{array}$ \\
\hline $\begin{array}{l}\text { Placing super-capacitors } \\
\text { (centre of gravity) }\end{array}$ & 4 positions \\
\hline
\end{tabular}

\section{CONCLUSION}

According to our experience and calculations achieving a better time per lap is possible, and, at the same time, the system is cheaper. This device can be called a "real recuperation unit", with smaller additional power which can be added during all possible moments at one lap. We can document this statement through calculations and simulations and through real-world results from Jerez.

\section{REFERENCES}

Internal documents of the MSR Engines Ltd. 